\title{
Comparative tests for horizontal stiffness of elastomeric bearings
}

\author{
Aleksandr Shuvalov, Larisa Safina and Mikhail Kovalev* \\ Moscow State University of Civil Engineering, Yaroslavskoe shosse, 26, Moscow, 129337, Russia
}

\begin{abstract}
We needed to determine physical and mechanical characteristics of elastomeric bearings in order to create an accurate design models for structures mounted on elastomeric bearings. Methods and results of comparative tests for horizontal stiffness of elastomeric bearings, that were carried out both on real-size specimens and smaller scale models, are shown in the following article. Tests on real-size specimens were undertaken to prove the trustworthiness of test results acquired on smaller scale models.
\end{abstract}

\section{Introduction}

In the previous article called "Study of reinforced elastomeric bearings for structures in seismic areas" [1] authors have revised an issue of erecting a shopping and entertainment mall in seismic area. According to design, this building had a metal roof mounted on reinforced concrete structures. Use of rubber-steel supports called elastomeric bearings [2] was advised in order to decrease the influence of seismic loads on building. The effectiveness of such type of earthquake protection are considered in literature including regulatory documents such as EN 1337-3 [3], AASHTO LRFD Bridge Design Specifications 2012 [4], ISO 22762-1 [5].

We needed to determine physical and mechanical characteristics of elastomeric bearings via experiment in order to create an accurate design models for structures mounted on elastomeric bearings. Tests on real-size specimens were undertaken to prove the trustworthiness of test results acquired on smaller scale models.

\section{Methods}

Tests of real-size specimens with dimensions of 1100x1000x133 mm were carried out under supervision from Middle East Technical University Civil Engineering Department (Ankara, Turkey) [6] to determine the horizontal stiffness according to EN 1337-3:2005 (E) Annex F [3]. Two full-scale samples of elastomeric bearings were tested under shear. Thickness of the reinforcing steel plates was determined according to equation 12 EN 13373:2005(E) [3]. Test specimens were examined visually prior to and after testing, no defects were recognized in test pieces. The test was performed at a temperature of $t=+23^{\circ} \mathrm{C}$.

\footnotetext{
Corresponding author: kovalyov.mike@gmail.com
} 
Table 1 describes the dimensions and other properties of bearings.

Table 1. Properties of real-size elastomeric bearings

\begin{tabular}{|l|l|}
\hline Plan dimensions of test pieces & $1000 \mathrm{~mm} \cdot 1100 \mathrm{~mm}$ \\
\hline Edge cover & $5 \mathrm{~mm}$ \\
\hline Top and bottom cover & $3.5 \mathrm{~mm}$ \\
\hline Number and thickness of middle rubber layers & $6 \cdot 7 \mathrm{~mm}$ \\
\hline Total thickness of elastomer & $6 \cdot 7+2 \cdot 3.5=49 \mathrm{~mm}$ \\
\hline Number and thickness of reinforcing steel plates & $7 \cdot 2 \mathrm{~mm}$ \\
\hline Top and bottom steel plates thickness & $35 \mathrm{~mm}$ \\
\hline Elastomeric bearings height & $49+7 \cdot 2+2 \cdot 35=63+70=133 \mathrm{~mm}$ \\
\hline
\end{tabular}

The test bearings were placed symmetrically on each side of the vertical movable plate and the shear was applied in vertical direction as shown on figure 1.

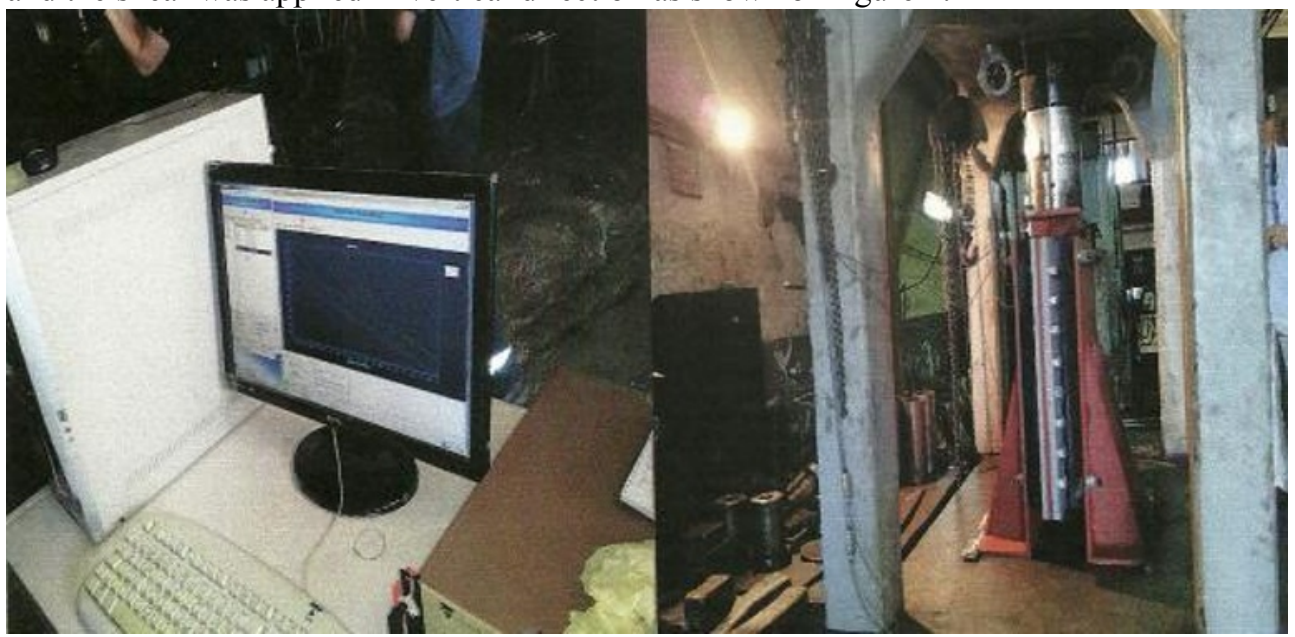

Fig. 1. Real-size specimens test setup

The bearings were subjected to shear at constant speed of $2 \mathrm{~mm} / \mathrm{sec}$ to the maximum test deflection $\mathrm{V}_{\mathrm{xm}}=44 \mathrm{~mm}$ and then returned to zero deflection. The horizontal deflection and force were continuously recorded. Shear modulus was determined between the horizontal displacement limits explained in EN 1337-3:2005 (E) part F.3.3 [3]. Total thickness of elastomer was $49 \mathrm{~mm}$ and the maximum horizontal displacement applied during the test was $44 \mathrm{~mm}$ (equation F.7.2 [3]). Three tests were conducted under the worst vertical load case which is $0 \mathrm{kN}$ (limit of uplift).

The horizontal stiffness can be computed from:

$$
K_{h}=\frac{G}{A \cdot T_{r}}
$$

where: $\mathrm{G}$ - the shear modulus; $\mathrm{A}$ - the area of bearing; $T_{r}-$ the total thickness of elastomer.

Tests on smaller scale models were carried out in NRU MSUCE. Specimens with dimensions of $275 \times 250 \times 133 \mathrm{~mm}$ (scale $1: 16$ ) were tested at the temperature of $23^{\circ} \mathrm{C}$ to determine horizontal stiffness using:

- testing unit with hydrocylinders installed into load frame;

- four displacement indicators;

- three steel plates with bolts sustaining two bearings specimens.

Specimens were connected using bolts and steel plates. The direction of shear was chosen along the long side of the bearing. Displacement indicators were fixed on the endpoints of connection between steel plate and elastomeric bearing specimen. 
Figure 2 shows schematic representation of layers in the specimen. Figure 3 shows the scheme of test and the specimen in the load frame.

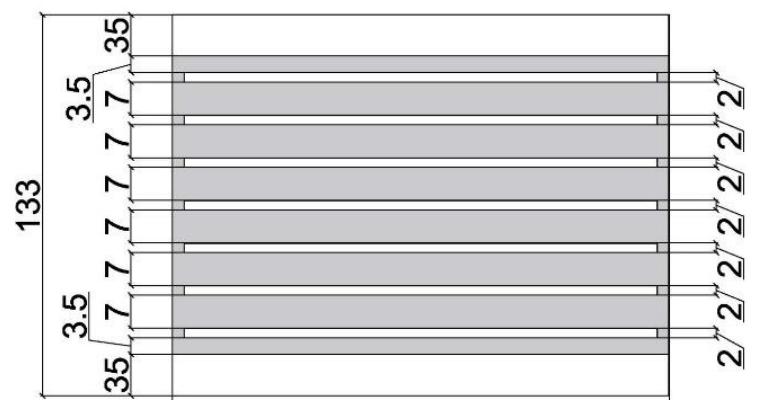

Fig. 2. Elastomeric bearing specimen
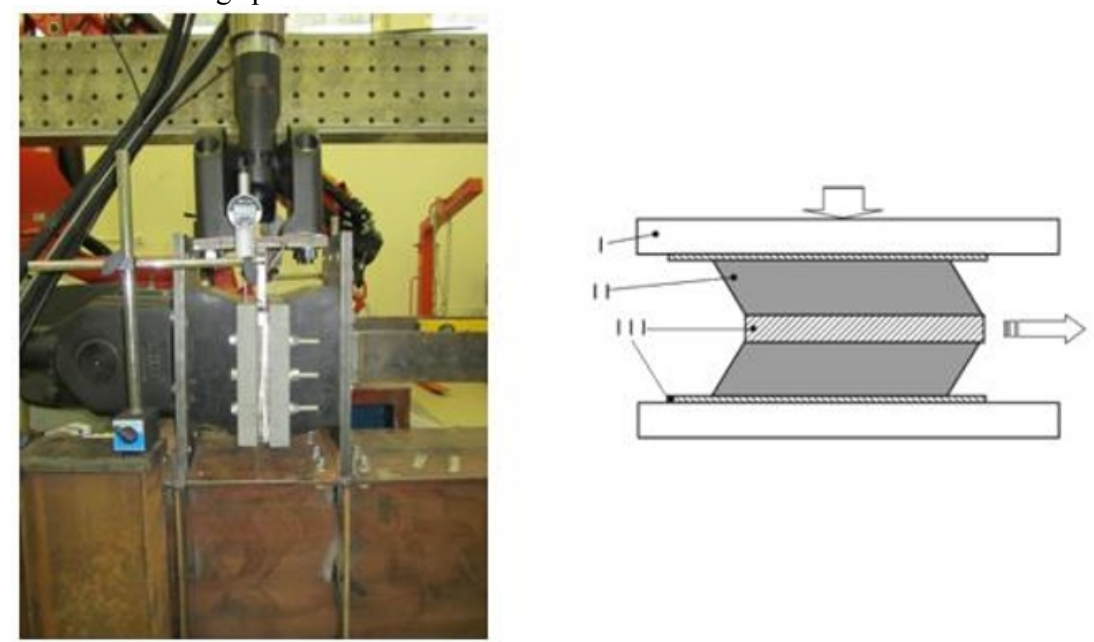

Fig. 3. Test of smaller scale sample of elastomeric bearing

Test for shear were carried on four pairs of specimens with hydrocylinder horizontal displacement up to $\mathrm{f}=40 \mathrm{~mm}$ and $\mathrm{f}=60 \mathrm{~mm}$. Tests were carried out with speed of 0.5 $\mathrm{mm} / \mathrm{sec}$. Each step of $10 \mathrm{~mm}$ the load was held for $10 \mathrm{sec}$. The deflection of the elastomer bearings was calculated as average value from showings of four displacement indicators. The horizontal stiffness can be computed from:

$$
K_{h}=\frac{F}{\Delta-\Delta_{\text {res }}}
$$

where: F - load at $40(60) \mathrm{mm}$ deflection; $\Delta$ - deflection of elastomeric bearing; $\Delta_{\text {res }}-$ residual deflection of elastomeric bearing.

Shear modulus can be computed from:

$$
G=\frac{K_{h} \delta}{A}
$$

where: $\delta$ - thickness of specimen excluding steel plates; A - area of one specimen.

\section{Results}

Results of tests of one real-size specimen are presented on figure 4 and in table 2. There was no detachment or bond failture in tested specimens within and after the tests. Test results indicated that bearings satisfy the requirements of the EN 1337-3 [3]. 

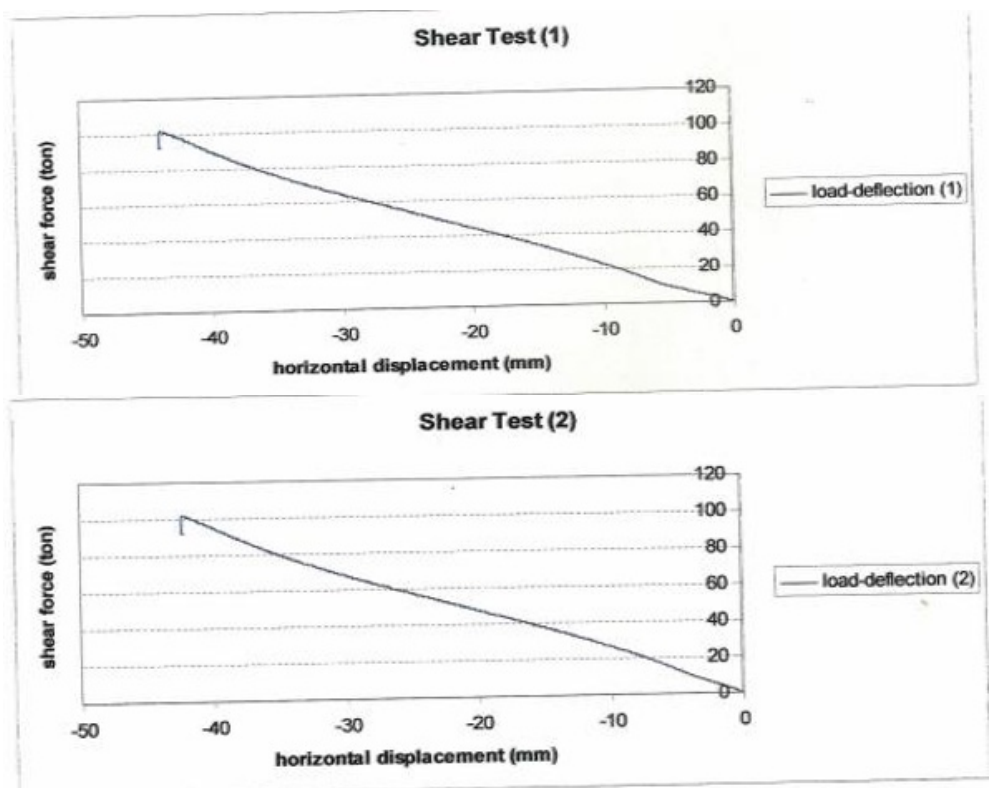

Shear Test (3)

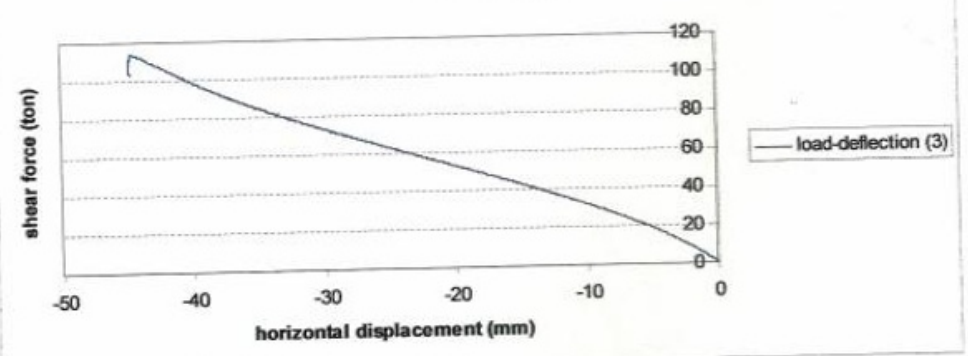

Fig. 4. Load-deflection diagrams for real-size specimens

Table 2. Horizontal stiffness of real-size specimen

\begin{tabular}{|c|c|}
\hline Test & Horizontal Stiffness \\
\hline 1 & 21.56 \\
\hline 2 & 21.86 \\
\hline 3 & 22.53 \\
\hline Average & 21.98 \\
\hline
\end{tabular}

Results of tests on smaller scale specimens are presented on figure 5 and in table 3 .

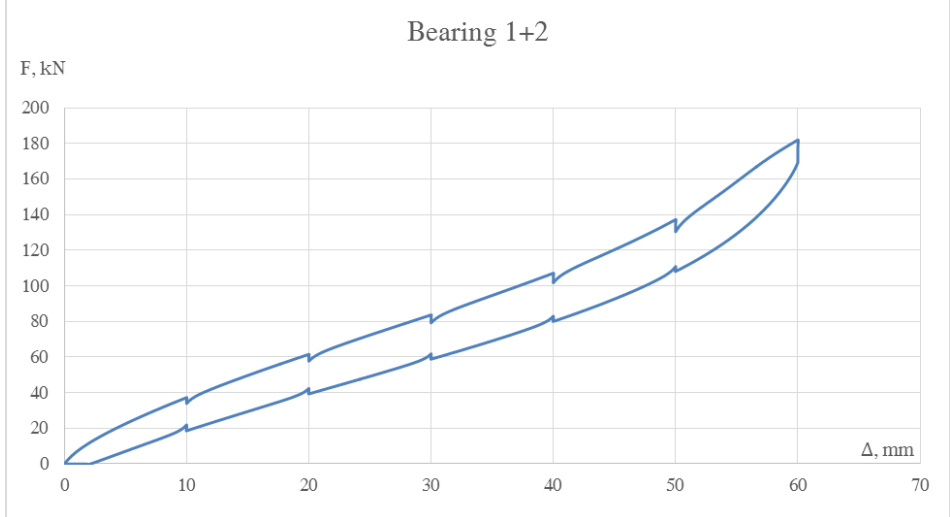



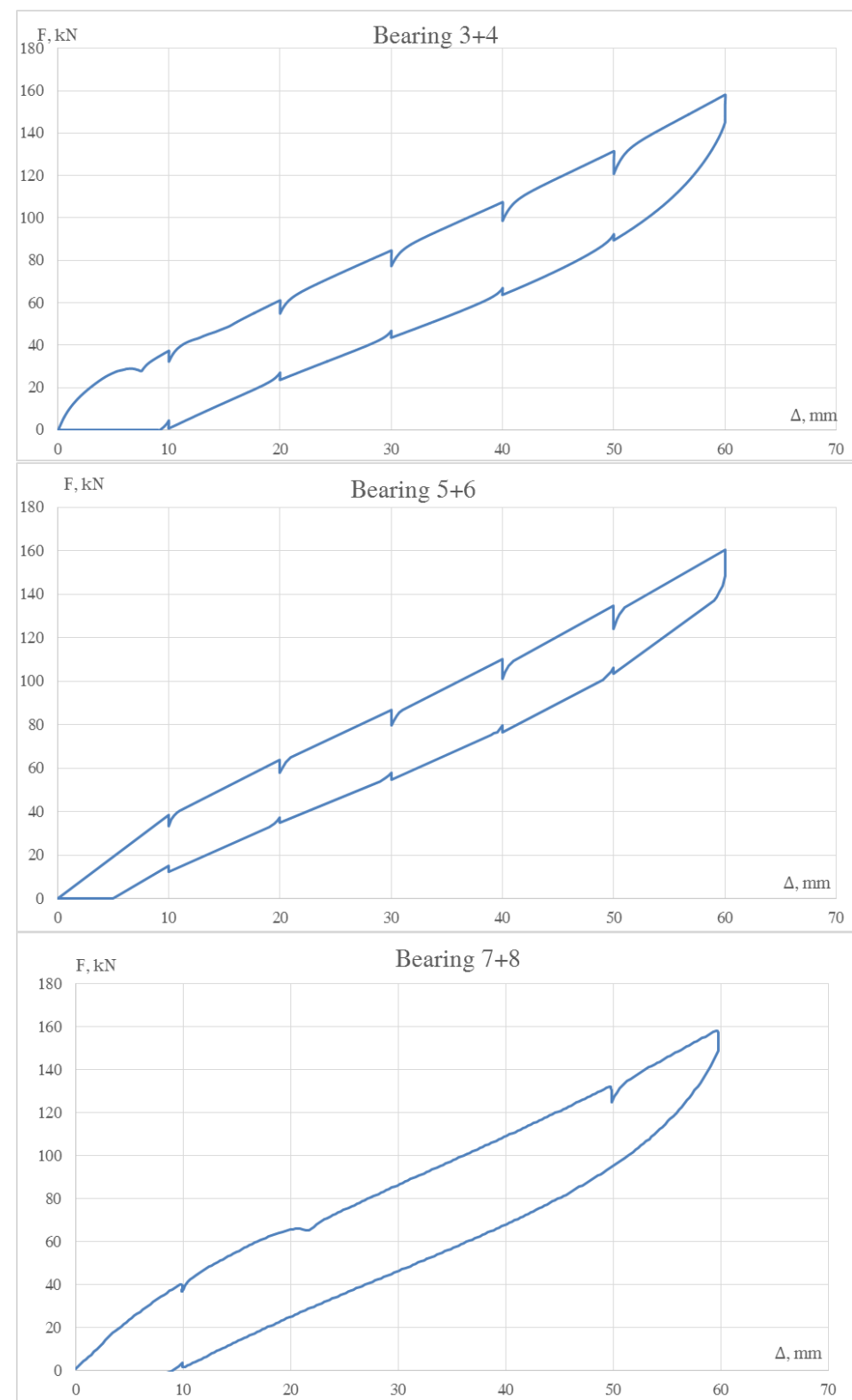

Fig. 5. Load-deflection diagrams for smaller-scale specimens

Table 3. Results of smaller-scale specimens tests

\begin{tabular}{|c|c|c|c|c|c|}
\hline Mark & $\mathrm{f}, \mathrm{cm}$ & $\Delta, \mathrm{cm}$ & $\mathrm{F}$, ton & $\mathrm{K}_{\mathrm{h}}$, ton/cm & $\mathrm{G}, \mathrm{MPa}$ \\
\hline \multirow{2}{*}{$1+2$} & 4.0 & 3.85 & 10.71 & 1.39 & 0.99 \\
\cline { 2 - 6 } & 6.0 & 5.95 & 18.20 & 1.53 & 1.09 \\
\hline \multirow{2}{*}{$3+4$} & 4.0 & 3.53 & 10.61 & 1.50 & 1.08 \\
\cline { 2 - 6 } & 6.0 & 5.47 & 15.47 & 1.41 & 1.01 \\
\hline \multirow{2}{*}{$5+6$} & 4.0 & 4.00 & 11.00 & 1.37 & 0.98 \\
\cline { 2 - 6 } & 6.0 & 5.40 & 16.05 & 1.49 & 1.06 \\
\hline \multirow{2}{*}{$7+8$} & 4.0 & 3.83 & 10.87 & 1.42 & 1.01 \\
\cline { 2 - 6 } & 6.0 & 5.45 & 15.82 & 1.45 & 1.04 \\
\hline
\end{tabular}




\section{Discussion}

Analysis of the diagrams for real-size specimens presented on figure 4 shows that:

- diagrams were recorded only for loading of the specimens;

- maximum horizontal deflections do not exceed $45 \mathrm{~mm}$;

- dependency of horizontal load from deflection on all figures is linear;

- horizontal stiffness in different tests is close and the maximum variation equals $4.3 \%$;

- values of horizontal stiffness satisfy the regulations of EN 1337-3.

Comparing the results of tests for real-size specimens and smaller-scale models we can state their good convergency.

Analysis of the diagrams for smaller-scale (1:16) models presented on figure 5 shows that:

- diagrams were recorded for both loading and unloading of the specimens with a hold of load after each $10 \mathrm{~mm}$ step;

- maximum horizontal deflections do not exceed $60 \mathrm{~mm}$;

- dependency of horizontal load from deflection on all figures is almost linear considering load jumps on holds in tests with the same conditions as the tests of real-size specimens (deflection up to $40 \mathrm{~mm}$ );

- corresponding values of horizontal stiffness for smaller-scale models have an close average value to the value for real-size specimens (divergence is $3 \%$ ) taking scale of 1:16 into account.

\section{Conclusions}

1. Horizontal stiffness acquired during tests of smaller-scale specimens by NRU MSUCE and real-size specimens by our colleagues in Turkey have good convergency. Maximum variation is $3.0 \%$.

2. Horizontal stiffness acquired during tests is higher than minimum permissible according to EN 1337-3 for both real-size specimens (minimum permissible is 20 ton/ $/ \mathrm{cm}$ ) and smaller-scale (1:16) specimens (minimum permissible is $1.25 \mathrm{ton} / \mathrm{cm}$ ).

3. Parallel tests to determine horizontal stiffness, which is the main characteristic of elastomeric bearing, on real-size specimens, their smaller-scale models and their comparison confirmed the trustworthiness of acquiring other physical and mechanical characteristics of elastomeric bearings on smaller-scale models.

All tests were carried out using research equipment of The Head Regional Shared Research Facilities of the Moscow State University of Civil Engineering (RFMEFI59317X0006).

\section{References}

1. Larisa Safina, Aleksandr Shuvalov, Mikhail Kovalev Study of reinforced elastomeric bearings for structures in seismic areas MATEC Web Conf., 193, ESCI 2018, (2018)

2. Lubica Nittmannová, Martin Magura, Experimental Verification of Elastomeric Bearings According to STN EN 1337-3, Procedia Engineering, vol. 156, 2016, pp. 280-287

3. EN 1337-3:2005 Structural bearings - Part 3: Elastomeric bearings

4. AASHTO LRFD Bridge Design Specifications, Customary U.S. Units, 7th edition

5. ISO 22762-1:2010 Elastomeric seismic-protection isolators - Part 1: Test methods

6. Technical report for real-size specimens tests, MIDDLE EAST TECHNICAL UNIVERSITY Civil Engineering Department (Ankara, Turkey) 